\title{
EDUCACIÓN, DISENSO Y POLÍTICAS DE DISCAPACITACIÓN
}

\author{
Patricia Claudia Brogna \\ Universidade Nacional Autónoma do México - UNAM
}

\begin{abstract}
Resumen
Este artículo analiza la relación entre los cambios económicos, políticos y culturales - a partir de la naturalización de los postulados neoliberales más radicales - con el rol de la educación en los procesos de discapacitación. ¿De qué modo es posible que la educación, como espacio de transmisión de saberes socialmente valiosos escape de los imperativos de conocimientos estandarizados globalmente evaluables y reconfigure su práctica de libertad en el rescate de concepciones del buen vivir, de comunidad y copertenencia, pagando una revisión crítica del "devenir negro del mundo" así como un consenso social nuevo y más justo?
\end{abstract}

Palabras clave: educación, neoliberalismo, nuevos consensos, procesos de discapacitación.

\begin{abstract}
This article analyzes the relationship between economic, political and cultural changes - from the naturalization of the most radical neoliberal postulates - with the role of education in the processes of disability. How is it possible that education, as a space for the transmission of socially valuable knowledge, escapes the imperatives of globally evaluable standardized knowledge and reconfigures its practice of freedom in rescuing conceptions of good living, community and co-belonging, paying a critical review of the "becoming black of the world" as well as new and more just social consensus?
\end{abstract}

Keywords: education, neoliberalism, new consensus, disability processes.

\section{Resumo}

Este artigo analisa a relação entre mudanças econômicas, políticas e culturais - da naturalização dos postulados neoliberais mais radicais - com o papel da educação nos processos relativos à deficiência. Como é possível que a educação, como um espaço para a transmissão de conhecimento socialmente valioso, escape dos imperativos do conhecimento padronizado globalmente avaliável e reconfigure sua prática de liberdade ao resgatar concepções de bem-viver, comunidade e co-pertencimento, pagando uma revisão crítica do "tornar-se negro do mundo", bem como um consenso social novo e mais justo?

Palavras-chave: educação, neoliberalismo, novo consenso, processos de incapacidade. 


\section{Introducción}

En el año 2006, publicaba una segunda tesis (Brogna, 2006) que proponía construir la discapacidad no como un atributo del sujeto sino como una posición que, dentro del espacio social, le es asignada a ciertas personas a partir de la confluencia de tres aspectos: la particularidad biológica o de conducta de un sujeto, aspecto cultural normativo y el económico-político de la sociedad en el que la persona vive.

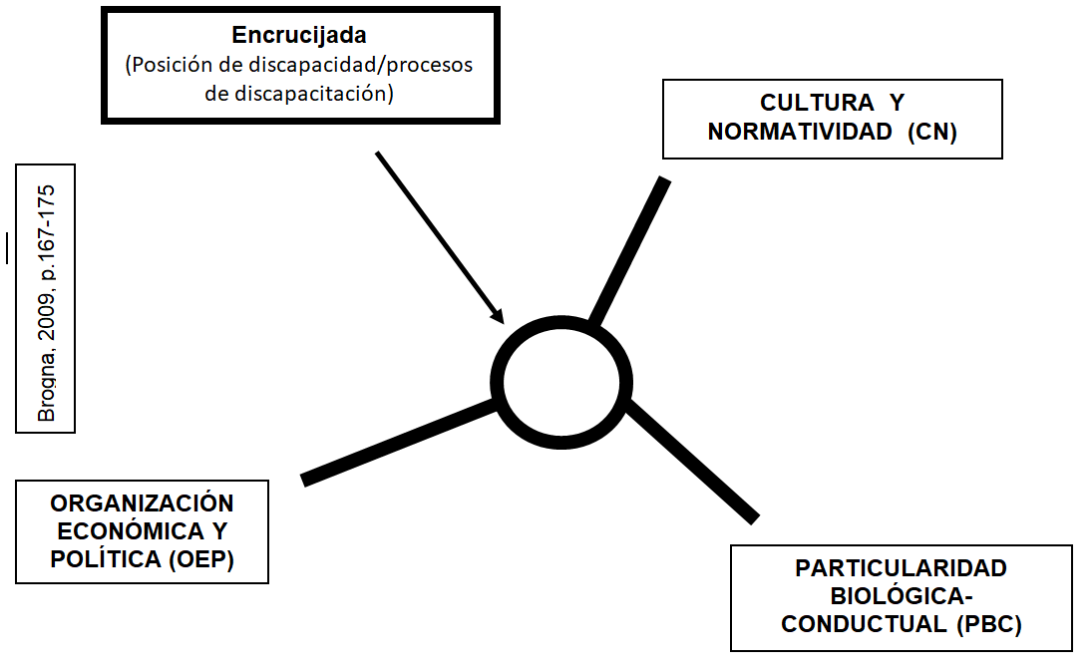

La posición de discapacidad, lugar arbitrario y contingente que se asigna a determinados sujetos en función de sus particularidades biológicas o de conducta, debe analizarse desde una perspectiva compleja en su interrelación con la cultura y la normatividad a partir del significado socialmente compartido de la diferencia y de las prescripciones sobre qué debe hacerse con ella; considerando las representaciones sociales, los esquemas cognitivos, los valores, las creencias, las normas así como los procesos de asignación identitaria y de invalidación social. El tercer elemento de esta complejidad es la organización económica y política (OEP), en referencia a los mecanismos de "exclusión - inclusión", a los postulados políticos y de políticas dominantes (por ejemplo democracias con fuertes regímenes de bienestar), al tipo de sistema económico, a la distinción entre sociedades alta o escasamente diferenciadas (en contextos rurales o urbanos, por ejemplo), entre otros factores.

La posición como lugar ocupado "en cada campo en relación con el capital específico que allí está en juego" (Gutiérrez, 1994, p. 48), "en el espacio social, es decir en la estructura de distribución de las diferentes especies de capital, que asimismo son armas, ordena las representaciones de ese espacio y la toma de posición en las luchas para conservarlo o transformarlo" (Bourdieu, 1997, p. 25) resulta, como mencionamos, arbitrario y contingente, y dependerá al igual que los otros elementos del sistema, de su mutua interrelación. En un nivel de impacto microsocial, las identidades de los sujetos cuya particularidad se asigna a la 
posición de discapacidad han sufrido transformaciones epocales en función de la reconfiguración del campo ya que la identidad, según Giménez, depende “(d)el proceso subjetivo (y frecuentemente autorreflexivo) por el que los sujetos definen su diferencia de otros sujetos (y de su entorno social) mediante la autoasignación de un repertorio de atributos culturales frecuentemente valorados y relativamente estables en el tiempo". Los atributos particularizantes -de diferenciación- y de pertenencia social -de identificación- han adquirido nuevas significaciones y denotan mayores complejidades. (Brogna, 2009, p. 167175)

Analizar de este modo la discapacidad y los procesos de discapacitación en relación a la educación y a los disensos latinoamericanos demanda un ejercicio profundamente reflexivo y altamente consciente del investigador así como una vigilancia epistemológica y metodológica que permita producir un conocimiento posicionado y contextualmente situado tal como señala Sandoval:

Desde esta perspectiva, el conocimiento es parcial y "posicionado" ya que surge de las características semiótico-materiales de las posiciones y articulaciones a partir de las cuales conocemos y que estarían en constante transformación. Es decir, no existiría la posibilidad de conocer desde ninguna parte, siempre lo haríamos desde un cuerpo, un tiempo y un lugar. El conocimiento situado, al estar posicionado, tiene diferentes significados según el contexto en el cual se articula, de modo que su teorización, más que ubicarse en la confrontación estéril entre una suerte de universalismo racionalista y un particularismo relativista, se propone argumentar una mirada del conocimiento como "contextualmente situado", es decir, una visión epistemológica desde la cual todas las formas de conocer de nuestra vida social están situadas en un contexto histórico y corporal $(2013$, p. 37 $38)$.

La reconfiguración del campo de la discapacidad, en general, y de la posición, en particular, se hace evidente por transformaciones sufridas durante los últimos 13 años en dos de los aspectos que se condensan en esa encrucijada: tanto en el aspecto normativo, más que el cultural, como en los cambios políticos y económicos que se han dado en el mundo en general y en especial en los países de nuestra región.

\section{La vertiente cultural-normativa y su impacto en el aspecto político}

La Convención sobre los derechos de las personas con discapacidad que Naciones Unidas aprobó en 2006 impuso un cambio en la forma de concebir la discapacidad asumiendo los postulados largamente defendidos por el movimiento de personas con discapacidad que cuestionaban y subvertían la visión caritativa, médica y asistencial.

A partir de estos nuevos estándares inicia un período de traducción de la letra a acciones reales y efectivas para su implementación. Sin embargo, es evidente que los grandes pendientes que los distintos países arrastran en el cumplimiento de la Convención navegan 
en un horizonte amplio y desigual que -como sistema complejo- no podemos leer de manera aislada de los factores culturales, políticos y económicos.

El impacto de la Convención en las políticas nacionales depende de la obligatoriedad de su cumplimiento en normativas y políticas regionales y en la capacidad de estas comunidades para imponer incentivos o sanciones (como es el caso de la Unión Europea o la Mancomunidad de Naciones, Commonwealth). Traducir a políticas públicas efectivas los niveles de equidad, igualdad e inclusión que marcan la Convención depende, entre otros factores, de la progresividad o regresividad con las que los distintos gobiernos diseñan e implementan esas políticas con perspectiva de derechos.

La incidencia y las acciones políticas de la sociedad civil de personas con discapacidad es otro aspecto que se ha modificado en cuanto al nivel, calidad y tipo de reclamo y demandas, aun cuando el derecho a consulta no es adecuadamente reconocido por los Estados.

A inicios del año 2019 un grupo numeroso de personas con discapacidad y sus familias, activistas, Organizaciones de sociedad civil, académicos y defensores de derechos humanos realizaron un pronunciamiento regional amplio y abierto por incumplimiento de principios de progresividad no regresividad que fue presentado ante los gobiernos de varios países y cuyo texto propone un diagnóstico vigente que ha sufrido escasos avances. El incumplimiento se evidencia en un "sistemático y peligroso recorte de derechos reconocidos" en la Convención sobre los Derechos de las Personas con Discapacidad de otros Tratados Internacionales y Regionales "y (que) repercute en el deterioro de la vida de las personas con discapacidad y sus familias promoviendo la pobreza, la discriminación y la exclusión educativa, laboral y social." De este modo "se diluyen los compromisos asumidos, se recortan presupuestos y se soslayan las obligaciones generales de los Estados no sólo para asegurar la progresividad sino para cumplir la obligación de no regresividad, principios que surgen de varios tratados de derechos humanos". Luego de enunciar brevemente la fuente de esos estándares el pronunciamiento concluye con un llamamiento a los Estados:

Por tales motivos hacemos un enfático llamado a los gobiernos a abandonar las acciones de simulación y a llevar adelante verdaderas políticas integrales, efectivas, progresivas y no regresivas que aseguren a la población con discapacidad el goce y ejercicio pleno de sus derechos en igualdad de condiciones que las demás personas, acompañadas de amplias campañas de concientización a la población en general. Del mismo modo convocamos a los líderes, integrantes y aliados del movimiento de personas con discapacidad de América Latina a considerar esta situación como un grave retroceso en sus derechos, un agravio generalizado frente a las demandas que se simulan atender y una pérdida de los escasos estándares de igualdad y participación que se habían conquistado en la región.

Una distinción necesaria resulta a partir de la polisemia del término "política" que en español hace referencia tanto a las acciones de gobierno (políticas, policies) como a los espacios de poder (política, politic). Según Aguilar Villanueva (2003, p. 30-33) mientras "las 
relaciones sociales se constituyen por expectativas recíprocas (...) las relaciones estrictamente políticas están determinadas por las expectativas de los participantes respecto a los productos gubernamentales o políticas" y aclara: "la política se juega entorno a las políticas". Este espacio de puja por las políticas o acciones de gobierno (nacional, estatal, local, institucional) se transforma en una arena de lucha: la arena "política" de las políticas. En este espacio los discursos y las prácticas hegemónicas se enfrentan a aquellos emergentes, novedosos, disidentes. Según el modelo de la encrucijada los cambios producidos en el aspecto cultural normativo impactan en el aspecto político al otorgar una perspectiva de derechos como base para nuevas demandas políticas y de políticas. El campo de la discapacidad como "espacio de juego históricamente constituidos con sus instituciones específicas y sus leyes de funcionamiento propias" (Gutiérrez, 1994, p. 31) es un campo en constante transformación y las instituciones, especialmente la institución escolar, requieren tomar un rol activo y consciente -no ingenuo- en este espacio de disputa. Si el cambio normativo y contracultural que representa la letra de la Convención, no se traduce en un cambio en las relaciones sociales y políticas, en la visibilidad de la opresión y de la exclusión, entonces la aceptación del discurso de derechos es una máscara que no condice con las acciones de gobierno ni con la decisión política: es una simulación, el "como si" de las políticas públicas en discapacidad que oculta, bajo un barniz de cambio, la continuidad de acciones médico-asistenciales, de discursos y prácticas de segregación, de invalidación social, de discapacitación.

Más allá, la institución escolar y las políticas educativas -en su dimensión de formadoras para el mundo laboral- adquieren una proyección irrenunciable en tanto puente a una realidad que se presenta cada vez más precaria y desigual. En el caso de las personas con discapacidad, la continuidad de estrategias de educación segregada ha sido señalada por el Comité de Expertos de Naciones Unidas como una de los mayores obstáculos para lograr una inclusión educativa efectiva y de calidad que habilite para enfrentar un mercado laboral cada vez más precarizado y complejo.

\section{Los cambios en el mundo del trabajo}

Los aspectos sociales puestos a debate actualmente a través de movilizaciones, acciones colectivas, migraciones y demandas políticas y legales -como la relación con la naturaleza, la crisis de los estilos de vida eurocéntricos, las formas de producción, la fragmentación social, el desempleo y nuevas formas de esclavitud- toman un protagonismo indiscutible e interpelan tres de los pilares fundacionales del sistema político y social: un contrato social que priorice la igualdad, la división social del trabajo y el acceso a la educación como condicionantes -sino determinantes- de esa igualdad.

Sin embargo, las coyunturas políticas en el mundo transmiten lo ilusorio que ha resultado la aspiración de una igualdad reflejada en el aumento del desarrollo y la prosperidad, en un reparto equitativo de los bienes sociales y en la derrama económica de sus beneficios -sobre todo aquellos originados en modos de producción regulados por normas de 
gobierno y organizaciones de los propios trabajadores. Desenmascarada esa ilusión, queda frente a nosotros su verdadero rostro de falsa promesa ante el progresivo deterioro de las condiciones estructurales de vida.

Nos acercaremos a esta línea de análisis a partir de Robert Castel -filósofo, sociólogo, estudioso del psicoanálisis, cercano a las posturas críticas de Basaglia y otros exponentes de la antipsiquiatría- quien abordó "el orden psiquiátrico" como una de las maneras de dominio y sometimiento ante los intentos de subversión y transgresión: "la psiquiatría es ciertamente una ciencia política porque ha respondido a un problema de gobierno” (...). En 1995 Castel publica "Las metamorfosis de la cuestión social. Una crónica del asalariado" que, de manera notablemente clara, identifica y describe los cambios sociales de su contex to como una escala local de mutaciones por venir a escala global en términos de precariedad, vulnerabilidad, exclusión, desempleo: los cambios en el mundo del trabajo y en las relaciones sociales. Lo que Castel planteaba hace casi 25 años como posibilidad es hoy una realidad innegable:

es entonces posible que, más bien que en una reducción de desempleo, se desemboque en una elevación el nivel de calificación de los desempleados. hoy en día, no todo el mundo es calificado y competente, y la elevación del nivel de la formación sigue siendo un objetivo esencial, pero este imperativo democrático no debe disimular un problema nuevo y grave: la posible inempleabilidad de los calificados. (Castel, 1997, p. 340)

Con esta sentencia premonitoria Castel describe una situación cada vez más extendida y dificulta el análisis al relacionar grados de integración laboral y de pertenencia a redes sociales como factores que dibujan diferentes zonas en las que las personas pueden desplazarse o "caer" según esos factores se modifiquen:

He propuesto una hipótesis general para explicar la complementariedad de lo que ocurre sobre un eje de integración por el trabajo (empleo estable, empleo precario, expulsión del empleo) con la densidad de la inscripción relacional en redes familiares y de sociabilidad (inserción relacional fuerte, fragilidad relacional, aislamiento social). Estas conexiones califican zonas de diferente densidad de las relaciones sociales: zona de integración, zona de vulnerabilidad, zona de asistencia, zona de exclusión o más bien de desafiliación. (Castel, 1997, p. 347)

Actualmente, y en esa línea de ideas, Mbembe llama "nómadas del trabajo", "humanidad superflua" y "empresario de sí mismo" a estas multitudes que no temen la explotación sino el no ser explotadas (2016, p. 29). Mientras, Guy Standing nomina "precariado" a esta nueva clase social que alterna entre las zonas de vulnerabilidad, asistencia o exclusión en función de los cambios que sufra en el eje de integración por el trabajo que mencionaba Castel, aunque con redes familiares y sociales más densas.

Por otro lado, el cambio de régimen de un capitalismo industrial a un capitalismo financiero permite, según Pérez Sosto el aumento de la acumulación en detrimento de las condiciones de trabajo y el desplazamiento a la desocupación: “cuántos más trabajadores 
quedan fuera, más se acumula o se equilibra el sistema. La variable de ajuste no es sólo el salario, sino la existencia misma del asalariado". Señala la existencia de "más de 200 millones de desempleados. Entre ellos, 80 millones son jóvenes que buscan su primer trabajo" y en relación a quienes tienen trabajo la calidad señala la descomposición de los criterios del trabajo decente ya que "1,500 millones de trabajadores son vulnerables (la mitad de la fuerza laboral mundial), mientras 1,200 millones de personas trabajan, pero sobreviven con menos de 2 dólares diarios." (2018, p. 20-21)

En pocas décadas el consenso sobre el trabajo se ha modificado. Un cambio cultural apenas percibido por la sociedad ha revalorizado el trabajo "freelance", el "outsourcing", los trabajos por honorarios incluso como forma de contratación estatal por largos períodos (lo que hubiera supuesto una vinculación laboral generadora de derechos) y ha naturalizado la toma de créditos como puerta al consumo ante la cada vez más débil capacidad de compra a partir de los ingresos.

Aún conscientes de la situación planteada, si la educación escolarizada es un prerrequisito para acceder a mejores posibilidades de empleo y, a la vez, el ámbito laboral es uno de los espacios donde se ejerce mayor discriminación hacia los grupos en situación de vulnerabilidad cabe preguntarnos si las personas con discapacidad continuarán siendo excluidas de ambas "estructuras sociales dadoras de sentido", en términos de Castel profundizando su condición de invalidación social.

\section{Un mundo capitalista...}

El capitalismo moderno europeo-occidental y americano se distingue de otras prácticas capitalistas (orientales o de la Antigüedad) por un ethos marcado por la aspiración de una acumulación sin límite, "ganar todo lo que sea posible" (Weber, 2003, p.95-96). La ética protestante que según Weber maridaba con el espíritu del capitalismo, puede verse hoy transformada en la idea de meritocracia, de la individualización (una vida "hágalo usted mismo" (Beck, 2003) y del propio esfuerzo cuyos ejemplos se nos presentan como "casos de éxito". Las progresivas demandas de libre mercado, de desregulación, del libre juego de oferta y demanda, de la libre competencia y de no intervención estatal-demandas ampliadas a partir de los postulados neoliberales- fueron las bases y el prerrequisito para una promesa de desarrollo económico y social. La expectativa de generar una derrama de beneficios en la población era alimentada por esos casos excepcionales que se presentaban como posible generalidad. Las aspiraciones a la movilidad social, al pleno empleo fueron develándose en su imposibilidad a la vez que se hacían más evidentes las situaciones de "opresión y privilegio" que vivían los diferentes grupos y que quedaban naturalizadas al asumirse los criterios de fracaso o éxito individual para explicar las desigualdades. Menciona Braudel:

Como privilegio de una minoría, el capitalismo es impensable sin la complicidad activa de la sociedad. Constituye forzosamente una realidad de orden social, una realidad de orden político e incluso una realidad de civilización. Porque hace falta, 
en cierto modo, que la sociedad entera acepte, más o menos conscientemente, sus valores. (Braudel, 2012, p. 71)

Una manifestación aún más perversa es la evidente cercanía entre gobiernos y empresas, entre poder político y económico, la injerencia del mercado en la "cosa pública", la traducción de los asuntos públicos en mercancía: "El capitalismo sólo triunfa cuando se identifica con el Estado, cuando es el Estado". (Braudel, 2012, p. 72)

Las posiciones de opresión y privilegio que según Goodman (2015, p. 1-14) son dos caras de la misma moneda que deviene -a través de dinámicas relacionales- en la exclusión, inequidad y desigualdad hacia grupos que, respectivamente, tienen características que la sociedad subvalora o sobrevalora. Este sistema de opresión-privilegio opera de manera estructural en diferentes niveles; social, de formas y con efectos acumulativos e interseccionales en las desventajas o ventajas que representan para los grupos. Abberley (2008, p. 34-50) analiza la opresión hacia el grupo de personas con discapacidad, enfatizando especialmente la complejidad de un trato que se da en un locus corporal a partir de prácticas y políticas violatorias y esclavizantes, equiparables a la opresión racial o de género y nos compele a preguntarnos "quién se beneficia con esto", quién es "el principal beneficiario del orden social reinante" que en nuestro análisis no puede escapar a los factores económicos y políticos de nuestros contextos.

\subsection{Bajo el influjo neoliberal}

Los progresivos cambios políticos y económicos que el neoliberalismo impone en nuestras sociedades se suman a un cambio cultural que hereda y ahonda del discurso y las prácticas capitalistas: la individualización, la meritocracia, la aceptación de la sobreexplotación, del desempleo y la precariedad laboral en términos de empleos freelance o trabajadores "app". Como menciona Byung-Chul Han:

El neoliberalismo, como una forma de mutación del capitalismo, convierte al trabajador en empresario. El neoliberalismo, y no la revolución comunista, elimina la clase trabajadora sometida a la explotación ajena. Hoy cada uno es un trabajador que se explota a sí mismo en su propia empresa. Cada uno es amo y esclavo en una persona. También la lucha de clases se transforma en una lucha interna consigo mismo. (2014, p. 17).

Estos cambios en los modos de concebir las relaciones de producción, señala Han, "hace imposible la revolución social" ya que a partir "del aislamiento del sujeto de rendimiento, (...) no se forma ningún político con capacidad para una acción común”. En el mismo orden de ideas que la relación entre la ética protestante y el espíritu del capitalismo (Weber, 2003) o la vida hágalo usted mismo (Beck, 2003), Han añade que quienes fracasan en las sociedades neoliberales se responsabilizan y se avergüenzan "en lugar de poner en duda a la sociedad o al sistema". 
Para Mbembé las prácticas necropolíticas y el devenir negro del mundo son manifestaciones del cambio sistémico en el que la humanidad es desconcertada espectadora o víctima de extendidas políticas de la muerte y "de prácticas imperiales inéditas, que adoptan elementos tanto de las lógicas esclavistas de captura y de depredación, como de las lógicas coloniales de ocupación y de extracción, e inclusive lógicas de guerras civiles y de razas de épocas anteriores" (Mbembé, 2016, p. 28-30).

Bajo el dominio de las industrias del silicio y las tecnologías digitales, del imperativo de la inmediatez y de la expansión planetaria del devenir negro "el neoliberalismo descansa en la visión de que todos los eventos y todas las situaciones del mundo de la vida [pueden] estar dotadas de un valor en el mercado." (Vogl citado por Mbembé) Ya no son solo los bienes materiales: la intangibilidad de las mercancías queda representada en la capacidad de las redes sociales para convertir nuestra vida cotidiana en un producto consumible, para transformar a jóvenes youtuberos o practicantes de e-sport en influyentes millonarios. Estas excepciones se transmutan en promesas de regla, mientras cada vez más personas quedan excluidas y las evidencias confirman que -bajo el manto neoliberal- inevitablemente se resquebrajan los vínculos sociales, la identidad se entiende como relación entre elementos idénticos y no como copertenencia (Mbembé): aún en países desarrollados la inclusión de los ajenos y la soledad de los propios se convierten en un problema de política pública. Entre los cuatro rasgos de nuestro tiempo el autor señala tres que nos parecen centrales en nuestro análisis: el encogimiento del mundo y el cambio demográfico, la redefinición de lo humano y la introducción generalizada de herramientas computacionales. (Mbembé, 2018, p. 22-30)

Utilizando de manera magistral los medios masivos de comunicación, las nuevas tecnologías y las redes sociales el neoliberalismo ha universalizado sus esquemas interpretativos, su habitus, con un discurso que se ha vuelto hegemónico. Sin embargo, cada vez más grupos en los diversos países se rebelan ante estas nuevas condiciones con manifestaciones convulsas y explosivas que son fuertemente reprimidas como observamos en imágenes que reeditan viejas escenas de violencia de Estado ya que -como se demostró con las dictaduras de Sudamérica en los años setentas- el sistema neoliberal no puede imponerse sin represión. Para Sassen (2018, p.14-15) la espiral de más pobreza, más desigualdad, más devastación demuestra que "estas expulsiones son el "filo sistémico" - un borde que existe dentro del sistema- y los espacios de invisibilidad conceptual”.

Los autores mencionados pagan por perfilar el contexto neoliberal que se relaciona directamente con los aspectos político, económico y cultural que según el mencionado modelo de la encrucijada reconfigura la posición de las personas con discapacidad en términos de mayor desafiliación.

\section{Hegemonías, disensos y consensos}

Según Laclau y Moffet (1985, p.176-194) el espacio discursivo en el que las luchas, choques y rupturas posibilitan neutralizar las imposiciones a partir de prácticas articulatorias que recuperen otras significaciones posibles, ofrece la madurez de articulaciones de sentido 
contrahegemónicas. Cuando estos consensos no se construyen en un plano de equidad entre los sujetos, sino a partir de la amenaza o del uso pleno de la coerción, entendida como el ejercicio de la fuerza física, los significados impuestos se transforman en una imposición hegemónica de sentido. Sin embargo, estos procesos que logran la imposición de una forma "natural" de ver el mundo, de un sentido común no son procesos acabados y abren la posibilidad a subvertirlos a partir de procesos contrahegemónicos. Los núcleos de articulación, vinculados a las relaciones sociales en función a demandas y reclamos de grupos que han tomado conciencia de su situación de sometimiento y opresión han tenido su más clara expresión en las luchas de clase, y por los derechos civiles y políticos de los afrodescendientes norteamericanos y las mujeres. Sin embargo, más recientemente el heterosexismo, el capacitismo y el racismo han sido cuestionados como discursos hegemónicos basados en una articulación de sentido que revalora una única manera de hacer, de ser y estar en el mundo.

Abreviando de la descripción que Goffman realiza del estereotipo hegemónico de persona a inicios de los años '60s:

Por ejemplo, según consenso general en Estados Unidos, el único hombre que no tiene de qué avergonzarse de nada es un joven casado, padre de familia, blanco, urbano, norteño, heterosexual, protestante, que recibió educación superior, tiene un buen empleo, aspecto, peso y altura adecuados y un reciente triunfo en los deportes. (2001, p. 150).

Podemos identificar las características deseables y con base en ellas cuáles serán -en términos del autor- los sujetos desacreditados o desacreditables, aunque pocas han dejado de incidir en la representación de sujeto hegemónico, aunque aquellos que no cumplen con este perfil de "varón, urbano, blanco, ágil, exitoso, heterosexual y cristiano" puedan llegar muy excepcionalmente a espacios de reconocimiento y poder. De manera hegemónica se mantienen en una posición subalterna, subordinada y desvalorizada de otro que no es como nosotros.

Sin embargo, de la misma manera que el modelo neoliberal (en sus facetas política, económica, cultural y social) parece naturalizar el devenir negro del mundo, a los supernumerarios y al precariado como nueva masa heterogénea y dispersa de personas a lo largo de toda la extensión del tejido social es también cada vez más amplio el consenso, surgido a partir de vínculos sociales desarticulados y descentralizados que se gestan a través del espacio contingente y efímero de las redes sociales. Estos nuevos activismos han logrado una mayor madurez entre algunos grupos, o alrededor de ciertas demandas. Si la pérdida de entidad que la noción de clase otorgaba para señalar la desigual distribución de capitales, fortaleció la popularización de los postulados del neoliberalismo y su potencial de fragmentador social, las nuevas demandas sociales develan que la inequidad subsiste bajo formas renovadas de opresión de unos y privilegios de otros. Es un campo incipiente en el estudio del activismo y de los movimientos sociales la manera en que la sociedad utiliza las propias herramientas tecnológicas del sistema neoliberal para organizarse en su contra. 
El estatus de alteridad, que Goffman definió en su lejanía de un ideal de "varón, urbano, blanco, ágil, exitoso, heterosexual y cristiano" se instaura como la dimensión óntica del ser ideal que al existir configura al otro. Cuestionar esta perspectiva nos permite a la vez entender la otredad en sentido relacional, en las luchas, choques y rupturas del espacio discursivo que mencionaban Laclau y Moffet (ibidem). Las significaciones contrahegemónicas a las articulaciones de sentido que naturalizan la dimensión óntica de la alteridad, las encontramos en los discursos que cuestionan el sexismo, el racismo, el capacitismo, y el clasismo, poniendo de manifiesto su construcción histórica y cultural como manifestaciones de desigualdades con raíz común tal como analiza Adams en sus compilaciones sobre estos "ismos" (Adams, 2000).

En el orden de ideas precedente la educación tiene entonces un rol contradictorio y conflictivo: a la vez que se le demanda un papel emancipador en términos freireanos, debe cumplir el mandato de reproducir - y hacer obedecer - las desigualdades sociales (Bourdieu y Passeron, 1998; Bourdieu y Passeron, 2008; Álvarez, 1991, p. 13-54, 209-234).

Frente a este escenario la propuesta de nuevos pactos democráticos y nuevos consensos sociales adquiere su condición de reto irrenunciable y complejo.

\section{De contratos, acuerdos y pactos}

Heredadas de Hobbes, Locke y Rousseau las ideas de articular un consenso entre gobernantes y gobernados y entre la propia comunidad representan una inacabada aspiración en nuestras sociedades. Lograr un consenso más o menos unánime sobre lo que es "el bien común", sobre la forma en la que se llevarán a cabo políticas de identidad (Fraser, 2008), neutralizar el mandato hegemónico de los mercados y el discurso neoliberal, redistribuir con el objetivo de lograr la equidad y limitar la concentración de capitales, y desmontar las prácticas de privilegio de ciertos grupos a expensas de la opresión de otros, en el entendido de que los recursos son limitados y que la acumulación por parte de algunos grupos o sujetos siempre será a expensas de la carencia que sufran otros.

Queda claro que los procesos discursivos hegemónicos que logran la imposición de sentido sobre una forma de visión del mundo no son procesos acabados: como disputa de poder involucran luchas, coerción, rupturas. En las naciones modernas, el Estado como poder soberano desnuda "(1)a crisis de la modernidad, que es la copresencia contradictoria de la multitud y un poder que quiere reducirla al gobierno de uno, es decir, la copresencia de un nuevo equipo productivo de subjetividades libres y un poder disciplinario que quiere explotarlo, no se pacifica o resuelve finalmente por el concepto de nación, más que lo hizo por el concepto de soberanía o Estado. La nación sólo puede enmascarar ideológicamente la crisis, desplazarla, y diferir su poder" (Hard y Negri, 2016, p. 117) Esta referencia a la contradictoria copresencia de multitudes bajo la órbita de un poder institucional central y de poderes fácticos que presionan por sus intereses paga para comprender que el consenso social debe entenderse en su mutable fractalidad. Para los autores "la soberanía ha adquirido una nueva forma, compuesta por organismos nacionales y supranacionales unidos por una única 
lógica de dominio" que llaman imperio. Esta afirmación sobre una lógica de dominación global cuestiona, en términos de Fanon, si no estamos ante una parcialidad formulada como absoluta (2001, p. 35), ante la razón negra de Mbembé, esclavista depredadora y extractiva (...), ante una reedición colonial que se nos presenta desprovista de su dimensión e intereses económicos. Sería necesario preguntarnos: esta concepción de imperio ¿qué y cuánto tiene en común con la idea de colonialismo? ¿de qué modo impulsa a multitudes a la zona no ser de Fanon? (2001, p. 42).

Los enormes grupos de personas que cruzan mares y territorios como migrantes o desplazados por motivos económicos o por situaciones de guerra, deben asumir que la crisis se transformará para ellos en un estado permanente. En España -por ejemplo- más de 10,000 menores extranjeros son indocumentados y se transformarán en adultos sin papeles, desafiliados, habitantes del no $\operatorname{ser}^{3}$.

En este escenario, las posiciones de poder para negociar, consensuar e imponer una idea de "bien común", para impulsar acuerdos sociales y pactos democráticos se debaten entre actores que ponen en juego diferentes capitales y dimensiones: ciudadanía, derechos humanos, inequidad, desigualdades de raíz común tanto la invalidación con base en el género, la raza, la etnia, la nacionalidad, la cultura, la capacidad. Ampliando y complementado la idea del bien común, Federici llama nuestra atención sobre lo común, como aquello que se comparte y cohabita a la vez que fomenta "la cohesión y cooperación comunitarias" señalando que ha sufrido sucesivas políticas de cercamiento (cercenamiento) a partir de la apropiación de bienes, derechos y espacios comunes (tierras comunales) y de los procesos de privatización que limitan el acceso a los mismos. (2015, p. 20-21, 47).

\section{Educación para otros mundos}

Ante la pluralidad de mundos posibles, lo "otro" funge como apertura y alternativa. El complejo y desigual escenario que se recrea ante nosotros, y que intentamos pincelar en las páginas anteriores, puede obturar la posibilidad de imaginar formas, otras de cohabitar junto a otros en su copresencia. Esta premisa, que requiere ante todo un análisis crítico y alejado de aspiraciones de solidaridad y empatía, sólo podrá cumplirse a partir de nuevos acuerdos sociales sobre una redefinición de lo común, de lo justo, de la igualdad, de lo humano.

En este contexto la educación puede analizarse, en su potencialidad, desde distintas perspectivas. Como práctica social, permite asumir la responsabilidad de definir qué valores y conocimientos consideramos valiosos para transmitir a las nuevas generaciones. Sin embargo, como espacio simbólico y de poder reproduce las desigualdades sociales y enseña a los grupos subalternizados cuáles son los mandatos a obedecer (de clase, de género, de grupos, por ejemplo) según Álvarez Uría (1990, p. 13-54). Como sistema invita a revisar su historicidad, su institucionalidad, vertical y represiva cuestionando la visión hegemónica de una educación escolarizada y "evaluada" en el cumplimiento de objetivos y criterios de eficacia impuestos como estándar global. 
Las desigualdades en el acceso a una educación de calidad y a la escuela como instancia posibilitadora, representan, en otra escala, las desigualdades sociales. Este hecho innegable nos confronta con la necesidad de una toma de posición, con una toma de conciencia del "sentido de la posición de uno" en el campo, que es a la vez el sentido del lugar de los otros (Goffman citado por Bourdieu, 2007, p.131) y que permitiría recrear el espacio educativo como territorio de prácticas contraculturales y liberadoras que exploren nuevos consensos de lo común, nuevos acuerdos sobre el bien común.

En relación a los cambios en el mundo del trabajo que abordamos más arriba, es evidente que la escuela actual no sólo no garantiza ya una movilidad social ascendente sino que se transforma en el principal espacio de exclusión, de subjetivación deficitaria bajo parámetros capacitistas de inteligencia, y criterios de desarrollo de competencias y alto rendimiento, naturalizando el peso y la responsabilidad individual del fracaso siendo el caso de las personas con discapacidad donde esta realidad se hace más evidente.

\section{A modo de consideraciones finales: la vivencia y la experiencia no te da la conciencia.}

No abundaremos sobre las dificultades que persisten a partir de un sistema educativo que continúa aceptando la educación segregada para personas con discapacidad y que entiende que la diversidad humana debe organizarse en categorías y espacios que no (se) estorben.

La demora de los gobiernos en nuestra región en llevar a cabo verdaderas políticas de inclusión educativa se han ganado críticas y recomendaciones de diversos actores, en especial del Comité de Naciones Unidas que monitorea la implementación de la Convención y el cumplimiento de sus estándares.

Las múltiples barreras y obstáculos que deben sortear los estudiantes con discapacidad para avanzar en el sistema, lograr sus certificados y poder aspirar a una educación superior queda plasmada en la retrospectiva de los estudiantes con discapacidad que han logrado acceso a la educación superior. La mayoría de esas trayectorias están tapizadas por demandas judiciales y reclamos legales.

Un joven profesor - licenciado en educación física y activista del movimiento de personas con discapacidad, que por su condición es uno de los ejemplos en esa constante de demandas y juicios contra las distintas instancias del sistema - compartió en su Facebook la siguiente publicación:

Estoy recibiendo cada vez más casos de Universidades e Instituciones de Educación Superior que obstaculizan la formación de personas con discapacidad y también niegan titulaciones. Hay incluso una Universidad privada que ofreció pagar a una estudiante la matrícula de otra Universidad con tal que terminara su carrera en otra institución, y un instituto no universitario en donde los profesores parecen apostar cuando un estudiante con discapacidad abandonará la carrera. Después se quejan de mi tesis "militante" y me piden que retire el nombre de la 
Universidad Nacional de la Matanza de ella. Deseo que algún día las comisiones universitarias y no universitarias vinculadas a discapacidad, que dicen trabajar por y para el colectivo, tomen valor y se manifiesten sobre estas cosas." 4

Luego de todos los obstáculos que han sorteado en su trayectoria, es ahora la educación superior la que vuelve a llevar los pantalones e impedir el ingreso "al reino" de quienes acceden a ese espacio de generación y transmisión de conocimientos. El forzado contrato que, a regañadientes, aceptaban primero las instancias regulares de nivel de educación primaria, luego las de nivel medio y superior (sin dejarles de insistir a los padres y alumnos sobre lo beneficioso de una educación especial segregada) se reedita ahora -ante la "llegada de los bárbaros"- con estrategias de boicot o de una clara apuesta por el fracaso escolar. Sin embargo, también es evidente que la vivencia, como impronta; la experiencia, como instancia reflexiva individual, de ningún modo garantizan la conciencia política de ser sujeto de exclusión y opresión, ni la reacción colectiva de actuar socialmente en consecuencia.

El "poder-poder" (Brogna 2012), como la potencia y capacidad de lograr y que es siempre puesto en cuestión, se tensiona ahora en ese espacio común real y simbólico de una educación que, aún con todas las limitaciones en el complejo escenario presentado, brinda la posibilidad de obtener mayores capitales culturales, sociales, políticos, económicos.

En los medios de Argentina y Brasil fueron noticia los dichos de políticos en el sentido de que los pobres no llegan a la educación superior y que la misma debe mantenerse como espacio de privilegio para una elite. En el campo de lucha que representa la educación, y que es un subcampo fractal de lo social, podemos tomar una instantánea de esos discursos hegemónicos que se perpetúan, de las voces que intentan incluir nuevas narrativas, de los viejos acuerdos que separan a los privilegiados de los oprimidos y de los impulsos disidentes que promueven la posibilidad de pensar y construir formas alternas y más justas de lo común.

\section{Notas}

1. Este grupo se articula alrededor de instancias internacionales como la ONU y la OEA, entrelazando a diferentes actores que formaron parte de esos organismos durante el proceso de redacción de la Convención sobre los derechos de las personas con discapacidad, de la CEDDIS, y de gobiernos nacionales.

2. Para ver el pronunciamiento completo y las listas de firmas, así como los recibidos en diferentes países: https://www.facebook.com/noregresiondederechosendiscapacidad/posts/662195097568438?_tn__ K-R

3. "Un chico con un NIE [número de identidad de extranjero] es un chico al que podemos integrar y con el que podemos trabajar. Un chico sin un NIE es pura vulnerabilidad, invisibilidad y exclusión (...) "Una persona que no puede acceder a los recursos para la inserción está condenada a la marginalidad" (...) Ayoub Hicho, un joven marroquí que ha dormido en las calles de cuatro países, fue uno de estos niños. Estuvo acogido en España durante más de tres años, pero nunca tuvo su documentación en regla. A los 12 años estaba en Andalucía y a los 15 en Madrid. Pasó por tres centros de acogida y un piso. "Nadie me hizo los papeles. Siempre me decían 'espera, espera'. Mi partida de nacimiento y mi libro de familia siguen en Chipiona [Cádiz]. Nadie hizo nada con ellos", cuenta en perfecto español. Sin documentos, emprendió un periplo que le llevó a los servicios sociales de Holanda, Alemania y Francia, pero tampoco le fue bien. "Estoy seguro de que mi vida habría sido otra si hubiese tenido mis papeles", asegura. Recién cumplidos los 18 años ha decidido volver a España. Ahora es un adulto que habla seis idiomas, pero es más invisible que nunca. Fuente: https://elpais.com/politica/2019/11/18/actualidad/1574096323_979962.html?ssm=FB_CC\&fbclid=IwAR2ZPh_6bRS klU_Nz_WeHuxgGw1dOc1tD0oHa9NCFGI1ZAyGmBBHftkdVwE 
4. Recuperado de https://www.facebook.com/emiliano.naranjo/posts/2668370786558100

\section{Referencias}

ABBERLEY, P. El concepto de opresión y el desarrollo de una teoría social de la discapacidad en Superar las barreras de la discapacidad. BARTON, L. (coord.) 18 años de "Disability and society". Madrid: Ed. Morata, 2008, p. 34-50.

ADAMS, M.; BLUMENFELD, W.; CASTANEDA, C. Readings for Diversity and Social Justice: An Anthology on Racism, Antisemitism, Sexism, Heterosexism, Ableism and Classism. Nueva York: Routledge, 2000.

Agular Villanueva, L. F. La hechura de las Políticas, México: Grupo Editorial Miguel Ángel Porrúa, 2003.

ALVAREZ URÍA, F. y VARELA J. Arqueología de la escuela, Ediciones la Piqueta, España, 1990.

ARDITI, B. Post-hegemonía: la política fuera del paradigma postmarxista habitual. En Cairo Heriberto y Franzé Javier, Política y cultura, España, Madrid: Biblioteca Nueva, 2010, pp. 159-193.

BECK U., BECK- GERNSHEIM, E. La individualización: El individualismo institucionalizado y sus consecuencias sociales y políticas. España, Barcelona: Paidós, 2003.

BRAUDEL, F. La dinámica del capitalismo. México: FCE, 2012.

BOURDIEU P. Razones prácticas. Barcelona: Editorial Anagrama. 2007, p. 25

BOURDIEU P. Poder derecho y clases sociales, en Cosas dichas. Argentina: Editorial Gedisa. 2007.

BOURDIEU P. y PASSERON, J., La reproducción. Elementos para una teoría del sistema de enseñanza, Fontamara, México, 1998.

BOURDIEU, P., y PASSERON, J., Los herederos, México, Siglo XXI, 2008.

BROGNA, P. La discapacidad: ¿una obra escrita por los actores de reparto? El paradigma social de la discapacidad: realidad o utopía en el nuevo escenario latinoamericano, Tesis Maestría, UNAM, 2006.

BROGNA, P. Las representaciones de la discapacidad: La vigencia del pasado en las estructuras sociales presentes. En: BROGNA, P. (Comp.). Visiones y revisiones de la discapacidad. México: FCE, 2009, p. 157187.

HAN, B., Psicopolítica, Neoliberalismo y nuevas técnicas de poder, Barcelona, España: Herder, 2014.

CASTEL R. La Metamorfosis de la Cuestión Social. Barcelona, España: Paidós, 1997.

FANON, F. Los condenados de la tierra. $4^{\mathrm{a}}$ ed., México: FCE, 2018.

FEDIRICI, S. Calibán y la bruja. Mujeres, cuerpo y acumulación originaria, Buenos Aires, Argentina: Ed. Tinta Limón, 2015.

FRASER N. Nuevas reflexiones sobre el reconocimiento En New Left Review, Núm. 4, septiembre-octubre, 2000, p. 55 a 68. Disponible en: https://newleftreview.es/issues/4/articles/nancy-fraser-nuevas-reflexionessobre-el-reconocimiento.pdf

FRASER N. La justicia social en la era de la política de identidad. En Revista de Trabajo, Año 4 Número 6 , agosto - diciembre 2008, pp. 83 a 99. Disponible en: http://trabajo.gob.ar/downloads/igualdad/08agodic_fraser.pdf

GLOBAL WITNESS, Informe: ¿ENEMIGOS DEL ESTADO? De cómo los gobiernos y las empresas silencian a las personas defensoras de la tierra y del medio ambiente, 2019. Disponible en:https://www.uniminutoradio.com.co/wp-content/uploads/2019/07/Enemigos_del_Estado.p df

GOFFMAN, E. Estigma: La identidad deteriorada, Buenos Aires, Argentina: Ed. Amorrutu/editores, 2012. 
GOODMAN D. Oppression and Privilege: Two Sides of the same coin, Journal of International $\begin{array}{lllllll}\text { Communication } & \mathrm{N}^{\circ} & 18, & \text { 2015, } & \text { p. } & \text { Disponible } & \text { en: }\end{array}$ http://www.dianegoodman.com/PrivilegeandOppression.

GUTIÉRREZ, A. Pierre Bourdieu. Las prácticas sociales. Argentina: Centro Editor de América Latina, 1994. HARDT, M., NEGRI, A. Imperio, Barcelona, España: Paidós Surcos, 2005.

LACLAU, E., MOUFFE, C., Hegemony and socialist strategy: towards a radical democratic politics, Inglaterra, Londres: Verso, 1985.

MBEMBÉ, A. Crítica de la razón negra, Buenos Aires: Futuro Anterior Ediciones, 2016.

MBEMBÉ, A. Políticas de enemistad, Barcelona, España, Ed. NED Nuevos Emprendimientos Editoriales, 2018.

PÉREZ, G. Perspectivas diversas en medio de un paisaje incongruente: escenarios de futuro para el mundo del trabajo. En PÉREZ, G. (Coord.) ¿Cuál es el futuro del trabajo? De la división social del trabajo al auge de la precariedad, Buenos Aires, Argentina: Ed. CICCUS, 2018.

ONU. Convención sobre los derechos de las personas con discapacidad. EEUU. Naciones Unidas. 2006.

SANDOVAL, J. Una perspectiva situada de la investigación cualitativa en ciencias sociales, Cinta de Moebio, n. 46, 2013, p. 37-46. Disponible en: www.moebio.uchile.cl/46/sandoval.html

SASSEN, S., "Sobre expulsiones”, entrevistada por / Interviewed by Francisco Díaz, Santiago, Chile, Revista ARQ, n. 98, abril 2018. Disponible en: https://scielo.conicyt.cl/pdf/arq/n98/0717-6996-arq-98-00014.pdf

STANDING, G. El precariado. Una nueva clase social, España: Ed. Pasado y presente, 2015.

WEBER M. La ética protestante y el espíritu del capitalismo. México: FCE. 2003.

\section{Correspondência}

Patricia Claudia Brogna: Professora da Universidade Nacional Autónoma do México (UNAM). Doutora em Ciências Políticas e Sociais pela UNAM. Coordenadora do Seminário Permanente sobre Deficiência (PUDH-FCPyS-UNAM). Linhas de pesquisa: Alteridade, deficiencia, desigualdade, exclusão, direitos humanos, educação e políticas públicas.

ORCID: 0000-0002-0873-6325

E-mail: patricia.brogna@politicas.unam.mx.

Texto publicado em Currículo sem Fronteiras com autorização da autora. 